\title{
UMA ANÁLISE DAS RELAÇÕES LABORAIS NOS PARQUES DE ENERGIA EÓLICA SOB A PERSPECTIVA DO EMPREGO VERDE E DO TRABALHO DECENTE
}

\section{AN ANALYSIS OF LABOR RELATIONS IN WIND ENERGY PARKS UNDER THE PERSPECTIVE OF GREEN EMPLOYMENT AND DECENT WORK}

Recebido: 21.08.2017

Aprovado: 28.10.2017

\author{
Flávia de Paiva Medeiros de Oliveira* \\ Cristina Paiva Serafim Gadelha Campos**
}

RESUMO: A preocupação com o resguardo do patrimônio ambiental tem assumido contornos cada vez mais relevantes, inclusive podendo ser destacados seus efeitos na seara laboral. Procurando associar ecologia e economia, a criação e manutenção de empregos verdes se revelam alternativas eficazes para garantir que atividades profissionais serão desenvolvidas sem causar prejuízos ao meio ambiente, bem como que os respectivos empregados gozarão de condições decentes de trabalho. O setor energético, por sua vez, através da exploração precípua de energias renováveis, detém potencial significativo para ofertar empregos verdes. Em vista disso, o presente trabalho tem como objetivo analisar se a exploração de uma das fontes renováveis largamente disponíveis no Brasil - qual seja, a eólica - tem o condão de contribuir com o esverdeamento laboral no país, notadamente sob a ótica do empregado, considerando as condições de trabalho às quais é submetido.

Palavras-chave: Emprego verde. Setor energético. Energia renovável. Energia eólica. Trabalho decente.

\begin{abstract}
The concern with the preservation of the environmental patrimony has assumed more and more relevant contours, including its effects in the labor market. Seeking to associate ecology and economics, the creation and maintenance of green jobs prove to be effective alternatives to ensure that professional activities will be carried out without causing harm to the environment, and that their employees will enjoy decent working conditions. The energy sector, in turn, through the primary exploitation of renewable energies, holds significant potential to offer green jobs. The aim of this study is to analyze whether the exploitation of one of the renewable sources widely available in Brazil - wind power - has the potential to contribute to the greening of labor in the

\footnotetext{
* Doutora em Direito do Trabalho pela Universidade de Valencia-Espanha; Mestre em Direito Constitucional pela Universidade Federal do Ceará (UFC); Professora Permanente do Programa de Mestrado em Direito e Desenvolvimento do Centro Universitário de João Pessoa-PB (UNIPE); Professora da Universidade Estadual da Paraíba (UEPB); Advogada. E-mail: < flaviadepaiva@hotmail.com>.

** Mestra em Direito e Desenvolvimento pelo Centro Universitário de João Pessoa-PB (UNIPE); Professora Substituta da Universidade Estadual da Paraíba (UEPB); Advogada. E-mail: < cristinacampos_@hotmail.com >.
} 
country, especially from the perspective of the employee, considering the working conditions to which it is subject.

Keywords: Green employment. Energy Sector. Renewable energy. Wind power. Decent work.

\section{INTRODUÇÃO}

As últimas décadas têm presenciado uma preocupação cada vez maior com a questão ambiental, sobretudo em decorrência da sensação de que os recursos naturais se revelam essenciais não somente à satisfação de necessidades básicas do homem, mas também ao desenvolvimento de suas atividades profissionais e garantia do seu bem estar. Nesse diapasão, e considerando a essencialidade da questão ambiental, o presente artigo procura demonstrar que a discussão acerca da necessidade de resguardar o patrimônio ambiental também tem alcançado, de modo significativo, o setor laboral.

A preocupação com a continuidade do usufruto dos recursos naturais tornou premente a necessidade de a seara trabalhista também dar sua parcela de contribuição à preservação da integridade do meio ambiente, prezando pela conciliação entre os postulados naturalmente relativos ao campo profissional - seja sob o ponto de vista dos empregadores, que visam o lucro, seja sob a ótica dos empregados, que merecem laborar sob condições decentes. Unindo tais anseios, torna-se possível falar em empregos verdes, os quais procuram satisfazer os trabalhadores de determinado setor, garantindo-lhe condições decentes de trabalho (o que pressupõe o atendimento dos anseios de quem labora e também do empregador, que optou pela contratação daquele), e garantir que o patrimônio ambiental não sofrerá com o desenvolvimento de atividades profissionais.

Ainda que a ideia de efetivar e difundir a criação ou a manutenção de empregos verdes soe interessante, necessário se faz analisar se suas características permitem que sejam observados em quaisquer atividades profissionais, ou mesmo quais seriam aquelas que permitem sua observância.

Por outro lado, especificamente quanto ao presente trabalho, destacando que filtrar a compatibilidade entre as diversas atividades laborais e a possibilidade de comportarem empregos verdes é propósito bastante amplo, optou-se por conferir foco específico ao setor energético, notadamente ao sistema de produção de energia através da utilização dos ventos.

Nesse sentido, este artigo tem como objetivo verificar se a geração de energia eólica garante empregos verdes, o que compreende o resguardo do patrimônio ambiental associado ao oferecimento de condições decentes de labor aos empregados do ramo. Para tanto, está baseado no desenvolvimento de pesquisa bibliográfica, leitura formativa e utilização dos métodos dedutivo e qualitativo. 


\section{PROTEÇÃO AMBIENTAL $X$ TRABALHO DECENTE: EQUAÇÃO INDISPENSÁVEL AOS EMPREGOS VERDES}

A geração de empregos verdes nasce, no âmbito do ordenamento jurídico pátrio, como decorrência do princípio da sustentabilidade, bem como axioma normativo constitucional, concedido pela a ordem econômica (art. 17o, da Constituição vigente), que se fundamenta na valorização do trabalho humano para promover existência digna, através da preservação do meio ambiente. Não obstante, os valores sobre os quais se funda a ordem econômica, estruturada constitucionalmente, não representa apenas um axioma observado a nível interno, mas reflete uma preocupação internacional que vem sendo discutida pela Organização Internacional do Trabalho (OIT), através do Relatório Empregos Verdes (PNUMA, 2008).

O mencionado relatório classificou como verdes os empregos "que reduzem o impacto ambiental de empresas e de setores econômicos para níveis que, em última análise, sejam sustentáveis" (PNUMA, 2008, p. 5). A empregabilidade verde se espraia por diversos setores da economia, desde a agricultura, indústria, serviços até o setor de administração. O pressuposto para ser considerado como tal é de que ele contribua para a preservação ou restauração da qualidade ambiental (PNUMA, 2008, p. 5-13).

A criação de postos de trabalho verde equaciona uma dupla preocupação do século atual, qual seja, a necessidade de proteger o meio ambiente natural que deve ser compatibilizada com a garantia de trabalho decente trabalho decente, considerado como tal aquele que assegura bem-estar e dignidade para os que exercem a atividade laborativa verde. O emprego verde reflete, portanto, uma conjugação da dimensão ambiental e social do princípio do desenvolvimento sustentável.

Para a OIT, a sustentabilidade vai mais além do caráter de preservação dos recursos naturais e adentra na perspectiva de avaliação do ambiente laboral e das transformações no mundo do trabalho, de modo que a evolução desse conceito é contínua e demanda constante aperfeiçoamento (OIT, 2012).

Nesse sentido, a Agenda 2030 para o Desenvolvimento Sustentável, no seu Objetivo no 8, enumera que a promoção do crescimento econômico inclusivo e sustentável, do emprego e do trabalho decente para todos é uma das metas que deve ser buscada a nível internacional (OIT, 2017, p. 2). Ademais, reconhece que é necessário, ao mesmo tempo, criar postos de trabalho capazes de assegurar a saúde e a segurança do trabalhador no seu espaço laboral, e incentivar a utilização de formas de energia que sejam respeitosas com o meio ambiente, o que deixa claro que a preocupação internacional da citada Organização não se resume apenas à garantia de condições de trabalho capazes de gerar benefícios econômicos para os trabalhadores, mas também, e principalmente, que as condições de trabalho criadas permitam um desenvolvimento integral do obreiro, tanto como ser individual, quanto como ser coletivo, que faz parte de uma sociedade que precisa assegurar a higidez do meio ambiente para as gerações presentes e futuras (OIT, 2017).

Essa nova perspectiva dos postos de trabalho, que atribui à sustentabilidade uma perspectiva social, ademais da ecológica (ambiental) que já é amplamente 
reconhecida, torna o caráter social do trabalho uma condição intrínseca para a emancipação da pessoa humana e se coaduna com a ideia defendida por Sen (2010, p. 55) de ver o desenvolvimento como um processo de expansão das liberdades reais que o ser humano desfruta.

A sustentabilidade passa, portanto, a gozar de um caráter unificador, na medida em que figura como um importante instrumento de transformação social e representa o modo por meio do qual se promove a unidade do ser humano com a natureza (Cruz e Bodnar, 2013, p. 51).

Esse fundamento unificador da sustentabilidade é a base sobre a qual a OIT erige a analise do emprego verde sob a perspectiva do trabalho decente, que, sob o aspecto prático, demanda uma avaliação desses empregos sob o prisma da segurança e saúde dos trabalhadores. Os empregos verdes podem gerar riscos laborais novos e emergentes, com relação aos quais os estudos científicos, ainda, não são capazes de precisar com clareza a probabilidade ou não de causar danos à integridade do trabalhador, de modo que a sustentabilidade em seu caráter amplo requer empregos que, além de gerarem uma baixa emissão de carbono no meio ambiente, sejam capazes de garantir postos de trabalho seguros e saudáveis para os trabalhadores (OIT, 2012, p. 3).

Há, portanto, um desafio a ser enfrentado com a criação desses novos postos de trabalho verdes, que se assenta na preservação da natureza, dos recursos naturais e dos ecossistemas, como também na necessidade de primar pelo desenvolvimento integral do trabalhador, começando por lhe assegurar emancipação social. A finalidade é fomentar uma integração do trabalhador, dos recursos utilizados para o trabalho, do próprio empreendimento com os recursos naturais e os ecossistemas, bem como alcançar o resguardo da integridade física e moral da pessoa trabalhadora.

Caracterizar um trabalho ser verde, do ponto de vista da perspectiva ambiental da sustentabilidade, não conduz necessariamente ao condão de enquadrá-lo como será verde, sob a dimensão social, especificamente, sob o viés da salubridade do meio ambiente de trabalho. Por isso, a OIT assevera que não se pode atribuir a etiqueta de verde a um trabalho que se enquadra como tal, quando analisado sob a dimensão ecológica, mas que não atende à perspectiva social da sustentabilidade e cita como exemplo a substituição de hidrofluocarbono por clorofluorcarbono nos processos de pinturas, que, malgrado seja mais sustentáveis do ponto de vista ambiental, não o são pelo prisma social, porque expõe o obreiro à substâncias mais cancerígenas, ademais de expô-lo a perigo de incêndio (OIT, 2012, p. 4).

Destarte, um posto de trabalho somente pode ser considerado como verde, em sua perspectiva ampla, segundo a OIT, quando for, ao mesmo tempo, sustentável pelo prisma ambiental e social, equacionando o respeito ao meio ambiente è pessoa trabalhadora. 


\section{O SETOR ENERGÉTICO COMO CAMPO FÉRTIL PARA EMPREGOS VERDES}

O propósito de associar a proteção ambiental à realização de atividades laborais que, além de oferecerem retorno financeiro satisfatório aos seus responsáveis, garantem que os respectivos empregados trabalhem sob condições decentes, suscita um prévio planejamento do vínculo empregatício que será efetivado. Saliente-se, todavia, que tal processo leva em consideração o quanto as escolhas relativas às matérias primas e demais instrumentos que serão utilizados são decisivas para o esverdeamento empregatício, o qual também sofre influência das diretrizes que orientam a infraestrutura do espaço laboral.

Procurando aplicar tais ideias especificamente ao setor energético, as atividades a ele relacionadas, notadamente as de produção e distribuição de energia, merecem estar estruturadas de modo a garantir a eficiência energética, a qual merece ser entendida como a obtenção de energia de qualidade e a baixo custo, além de oportunizar o usufruto dos recursos naturais energéticos equilibradamente pelas gerações atuais e futuras.

No que tange à ideia de equilíbrio entre o homem e seu entorno com o fito de que aquele seja capaz de resguardar sua própria vida, bem como as vidas das gerações vindouras, percebe-se que está sendo invocada a conotação de sustentabilidade em sua dimensão ampla (OLIVEIRA; CECATO, 2016, p. 208). Nesse sentido, cabe perceber a adequação entre o planejamento do setor energético capaz de torná-lo apto a ofertar empregos verdes e sua orientação conforme os postulados da sustentabilidade.

Com efeito, a sustentabilidade tem se apresentado como o norte que deve orientar a questão energética moderna, não só em virtude da premente necessidade de resguardar o patrimônio ambiental, mas, sobretudo, como uma forma de permitir que o processo de desenvolvimento (representado pela garantia de um padrão de vida satisfatório) siga adiante nos diversos Estados mundiais (KRAMER; FUSARO, 2010, p. 160). Dentre tais argumentos favoráveis à orientação sustentável da seara energética, destaque-se, oportunamente, sua relação com a capacidade de ofertar empregos verdes.

Corroborando essa ideia, merece destaque o fato de que a orientação sustentável da seara energética vem sendo apontada como responsável pelo posicionamento do respectivo ramo entre os dotados de maior potencial para a garantia de empregos verdes. Saliente-se, contudo, que o reconhecimento desta sua potencialidade está atrelado à organização do setor de modo a prezar pela utilização de fontes energéticas renováveis (PNUMA, 2008).

Nesse sentido, cabe observar a tabela abaixo, constante do relatório Empregos Verdes elaborado pelo PNUMA: 
Tabela 1: Avanço dos empregos verdes até o momento e potencial futuro

\begin{tabular}{|c|c|c|c|c|}
\hline & & $\begin{array}{l}\text { Potencial de } \\
\text { esverdeamento }\end{array}$ & \begin{tabular}{|l|} 
Avanços na \\
criaçăo de \\
empregos verdes \\
até o momento \\
\end{tabular} & \begin{tabular}{|l|} 
Potencial de \\
longo prazo \\
pard d criaýăo \\
de empregos \\
verdes \\
\end{tabular} \\
\hline \multirow[b]{2}{*}{ Energia } & Energias renovaveis & Excelente & Bom & Excelente \\
\hline & $\begin{array}{l}\text { Captura e seqũestro de } \\
\text { carbono }\end{array}$ & Moderado & Nenhum & Desconhecido \\
\hline \multirow{5}{*}{ Indústria } & Aco & Bom & Moderado & Moderado \\
\hline & Aluminio & Bom & Moderado & Moderado \\
\hline & Cimento & Moderado & Moderado & Moderado \\
\hline & Celulose e papel & Bom & Moderado & Bom \\
\hline & Reciclagem & Excelente & Bom & Excelente \\
\hline \multirow{4}{*}{ Transportes } & $\begin{array}{l}\text { Carros eficientes em termos de } \\
\text { consumo de combustivel }\end{array}$ & Moderado a Bom & Uimitado & Bom \\
\hline & Transporte público & Excelente & Limitado & Excelente \\
\hline & Ferroviário & Excelente & Negativo & Excelente \\
\hline & Aviaçao & Limitado & Limitado & Limitado \\
\hline \multirow{4}{*}{ Construçāo } & Prédios verdes & Excelente & Limitado & Excelente \\
\hline & Retormas & Excelente & Limitado & Excelente \\
\hline & Iluminaça & Excelente & Bom & Excelente \\
\hline & $\begin{array}{l}\text { Equipamentos e aparelhos } \\
\text { eficientes }\end{array}$ & Excelente & Moderado & Excelente \\
\hline \multirow{3}{*}{ Agricultura } & $\begin{array}{l}\text { Atividades agricolas } \\
\text { sustentáveis de pequena escala }\end{array}$ & Excelente & Negativo & Excelente \\
\hline & Agriculturs orgânica & Excclente & Limitədo & Bom a Excelente \\
\hline & Serviços ambientais & Bom & Limitado & Desconhecido \\
\hline \multirow{3}{*}{ Silvicultura } & $\begin{array}{l}\text { Reflorestamento e } \\
\text { florestamento }\end{array}$ & Bom & Limitado & Bom \\
\hline & Agrofloresta & Bom a Excelente & Limitado & Bom a Excelente \\
\hline & Manejo tlorestal sustentável & Excelente & Bom & Excelente \\
\hline
\end{tabular}

Fonte: PNUMA, 2008

Como se vê com base na tabela acima colacionada, a seara energética, por meio da exploração de energias renováveis, apresenta um excelente potencial de esverdeamento, acompanhado de potencialidade de longo prazo também excelente no que tange à criação de empregos verdes. Já no que diz respeito ao aproveitamento das referidas fontes energéticas para a criação de empregos nesses moldes até o momento, percebe-se que embora satisfatório, poderia ser mais explorado.

É em face de tal constatação que se releva a importância de investimento em políticas ativas e pesquisas relacionadas ao usufruto de energias renováveis e sua valorização em detrimento dos combustíveis fósseis (PNUMA, 2008, p. o6). Máxime se torna seu valor ao verificar que a maior exploração da renovabilidade energética e criação de empregos verdes no ramo está precipuamente concentrada em países desenvolvidos e que empregam dinheiro público para tais fins, ao passo em que uma gama de países em desenvolvimento apresentam características naturais propícias à sua exploração, mas não a fazem satisfatoriamente (BETINI; CASTAGNA; TIEPOLO, 2012, p. 04).

Nesse diapasão, merece ser considerada a tabela que segue, a qual demonstra em quais países estão localizados empregos verdes relativos ao ramo energético, levando em consideração a quantidade dos mesmos, conforme a fonte renovável observada: 
Tabela 2: Estimativa de empregos no setor de energias renováveis, países selecionados e mundo

\begin{tabular}{|c|c|c|c|}
\hline Fontes renovâveis de energia & Mundo* & Paises Selecion & \\
\hline Eólica & 300.000 & $\begin{array}{l}\text { Alemanha } \\
\text { Estados Unidos } \\
\text { tspanha } \\
\text { China } \\
\text { DInamarca } \\
\text { Índia } \\
\end{array}$ & $\begin{array}{l}82.100 \\
36.800 \\
35.000 \\
22.200 \\
21.000 \\
10.000 \\
\end{array}$ \\
\hline Solar FV & $170.000 * \pi$ & $\begin{array}{l}\text { China } \\
\text { Alemanha } \\
\text { Espanha } \\
\text { Estados Unidos }\end{array}$ & $\begin{array}{l}55.000 \\
35.000 \\
26.449 \\
15.700 \\
\end{array}$ \\
\hline Solar térmica & Pclo menos 624.000 & $\begin{array}{l}\text { China } \\
\text { Alemanha } \\
\text { Espanha } \\
\text { Estados Unidos }\end{array}$ & $\begin{array}{l}600.000 \\
13.300 \\
9.142 \\
1.900\end{array}$ \\
\hline Biomassa & 1.174 .000 & $\begin{array}{l}\text { Brasil } \\
\text { Fstados I Inidos } \\
\text { China } \\
\text { Alemanha } \\
\text { Espanha } \\
\end{array}$ & $\begin{array}{l}500.000 \\
312>00 \\
266.000 \\
95.400 \\
10.349 \\
\end{array}$ \\
\hline Hidrelêtrica & Pelo menos 39.000 & $\begin{array}{l}\text { Europa } \\
\text { Estados Unidos }\end{array}$ & \begin{tabular}{|l|}
20.000 \\
19.000 \\
\end{tabular} \\
\hline Geotērmica & 25.000 & $\begin{array}{l}\text { Estados Unldos } \\
\text { Alemanha }\end{array}$ & $\begin{array}{l}21.000 \\
4.200\end{array}$ \\
\hline $\begin{array}{l}\text { Energias renovâveis como } \\
\text { um todo }\end{array}$ & Pelo menos 2.332 .000 & & \\
\hline
\end{tabular}

Fonte: PNUMA, 2008

Em vista disso, embora seja evidente a concentração dos empregos verdes decorrentes da exploração de energias renováveis em países que demonstram investir em pesquisas e políticas ativas relacionadas, merece momentâneo destaque o quanto é considerável a oportunidade do esverdeamento empregatício resultante da exploração de recursos energéticos que se renovam.

No que se refere ao Brasil, percebe-se que seu potencial para a geração de empregos verdes através da utilização de suas fontes renováveis merece ser mais utilizado, o que pode ser feito com base na reorganização de sua política energética, primando pela progressiva substituição de combustíveis fósseis pelo maior uso dos diversos recursos renováveis de que dispõe (BETINI; CASTAGNA; TIEPOLO, 2012, p. 04). Sendo assim, dedica-se a próxima sessão a analisar a compatibilidade entre o uso de uma das fontes energéticas disponíveis no país - qual seja, a eólica - e a possível ampliação do número de empregos verdes. 


\section{EXPLORAÇÃODOPOTENCIALENERGÉTICODOSVENTOSBRASILEIROS: UMA ALTERNATIVA PARA A CRIAÇÃO DE EMPREGOS VERDES NO PAÍ́S?}

Considerando que os benefícios advindos da efetivação de empregos verdes são variados e atingem diversos setores, bem como diante da constatação de que o campo energético, notadamente ao explorar energias renováveis, detém potencial significativo para garantí-los, resta a premissa de que cabe a valorização da geração energética renovável também sob o ponto de vista profissional, o qual é sensivelmente refletido na seara social.

Por outro lado, deve-se levar em consideração que a oferta de recursos energéticos renováveis varia conformea localidade observada, bem como que não apenas a quantidade disponível de tais bens naturais interfere na possibilidade de sua utilização para a produção de energia, mas também as condições sob as quais são ofertados pela natureza, tais como a rugosidade do solo, incidência de raios solares ou velocidade dos ventos (HINRICHS; KLEINBACH, 2008). Em outras palavras, o investimento na exploração de energias renováveis - seja com o fim precípuo de garantir empregos verdes ou com base em qualquer outro - demanda uma análise prévia dos fatores que interferem no seu usufruto, os quais são sopesados ao determinar a potencialidade de determinada região para garantir a geração energética com base nos recursos renováveis encontrados em seu território.

Nesse diapasão, além de existir a possibilidade de uma determinada localidade não contar com a oferta natural de fontes energéticas dotadas de renovabilidade, o que traz prejuízos ao propósito de imprimir tal característica à energia lá produzida, também pode ocorrer de apesar da presença natural de tais recursos em certa região, suas demais condições naturais bloqueiam total ou parcialmente o uso daqueles, resultando no seu baixo potencial para a produção de energia renovável (PEREIRA, 2012, p. 94). Cabe salientar, contudo, que a potencialidade local para a geração energética renovável também varia conforme a matriz analisada, sendo possível que uma mesma localidade apresente elevado potencial com relação à certa fonte e baixo potencial quanto à outra.

Em vista disso, desconsiderando, momentaneamente, qualquer discussão acerca da importância de explorar as fontes renováveis disponíveis no Brasil, a extensão das terras brasileiras e a aparente disponibilidade de ventos no território nacional podem resultar na presunção de que o Estado detém elevado potencial para a produção de energia através de tais recursos - o que favoreceria a existência de empregos verdes no país, pelo menos sob a ótica ambiental. Somando tal premissa à ideia de que se trata da obtenção do referido bem essencial garantindo que sua principal matéria prima não se esgotará ou provocará degradação ambiental, cabe uma maior investigação quanto às consequências ambientais resultantes do mencionado processo produtivo, bem como com relação ao conjunto de fatores naturais brasileiros que nele interferem, os quais traduzem o potencial eólico nacional.

Sendo assim, as próximas linhas desta sessão serão dedicadas à análise das decorrências positivas e negativas da utilização dos ventos para a produção energética, sendo seguidas por considerações destinadas a verificar o potencial pátrio para a sua 
exploração. Saliente-se que tais considerações se revelam valiosas para verificar a instrumentalidade do sistema produtivo eólico para efetivar empregos verdes no Brasil.

Considerando que a fonte eólica é limpa, sua utilização para produzir energia, ainda que em grandes quantidades, não implicará no lançamento de gases de efeito estufa na atmosfera, ou mesmo de demais recursos poluentes e reprováveis pela ideia do desenvolvimento sustentável (HINRICHS; KLEINBACH, 20o8, p. 318). Tendo isso em vista, eis a relação de sua característica por hora posta em enfoque - decorrente de seu caráter limpo - com a evidência de que sua maior participação na matriz nacional é capaz de reduzir a poluição do ar, bem como de abater o aquecimento global (SIMAS; PACCA, 2013, p. 100).

Especificamente quanto ao fenômeno mencionado, percebe-se que reflete em nível mundial práticas adotadas no âmbito particular dos diversos Estados, motivo pelo qual é válida a afirmação de que tem origem em situações particulares, enquanto seus efeitos têm caráter difuso, podendo ser sentidos em localidades distantes de onde foram causados. Tendo isso em vista, e considerando que as decorrências do aquecimento global vão além de simplesmente provocar a elevação da temperatura terrestre (já que acarreta prejuízos à própria vida humana), a energia eólica representa uma opção eficaz para garantir a produção energética que vai além de favorecer o desenvolvimento social, uma vez que contribui com a preservação da atmosfera, enquanto bem ambiental (LOPEZ, 2012, p. 325).

Além disso, vindo a ampliar os efeitos ambientais positivos de uma possível expansão da indústria eólica nacional, a renovabilidade da energia dos ventos, por si só, lhe confere o caráter de fonte que não acarreta a diminuição quantitativa, ou mesmo qualitativa, dos recursos naturais (PEREIRA NETO, 2014, p. 35). Com efeito, os ventos representam a matéria prima principal da respectiva indústria, de modo que seria possível afirmar que o desenvolvimento de tal atividade utiliza-se de elementos que não impedem a utilização dos bens ambientais pelas gerações futuras, uma vez que seu insumo principal é inesgotável; nesse ponto, cabe a afirmação de que o impacto ambiental positivo da maior exploração eólica está associado ao favorecimento da sustentabilidade na perspectiva intergeracional (SOUZA; TEIXEIRA, 2015, p. 93).

Por outro lado, embora a renovabilidade, a inesgotabilidade e o caráter essencialmente limpo da energia eólica pressuponham sua conformidade com os postulados da sustentabilidade, não implicam na refutação de quaisquer ideias que apresentem a referida fonte como dotada de potencial para causar prejuízos ao patrimônio ambiental. Com efeito, ainda que suas características básicas lhe apresentem de modo favorável ao resguardo dos recursos naturais, permanece o risco de provocar efeitos danosos sobre o meio ambiente (GIDDENS, 2010, p. 169).

Inicialmente, cabe considerar que tais efeitos merecem ser reunidos sob a expressão impactos ambientais negativos, uma vez que representam alterações prejudiciais na integridade do patrimônio natural. Passando a exemplificá-los, vale destacar a poluição sonora (decorrente do barulho provocado pela movimentação dos aerogeradores que captam os ventos, causando ruídos cuja intensidade varia em 
conformidade com a altura dos rotores, rugosidade do solo, relevo, dentre outras características naturais, podendo assumir proporções elevadas, ou mesmo mínimas), a poluição visual (associada à infraestrutura necessária à produção energética, podendo impactar a paisagem de maneira direta ou afetá-la através das sombras resultantes da movimentação dos equipamentos), interferências eletromagnéticas, além de alterações na fauna e flora (CUSTÓDIO; VALLE, 2015, p. 26). Saliente-se, por oportuno, que maiores considerações acerca dos referidos impactos ambientais negativos do sistema de geração eólica merecem espaço na sessão imediatamente seguinte, ocasião em que serão analisadas as condições laborais ofertadas pelo trabalho no respectivo ramo.

Sendo assim, atendo-se às ideias já consideradas, cabe observar que ainda que tais consequências apresentem certa gravidade e acarretem a necessidade de rever decisões que repercutam na montagem de novos parques eólicos, ou mesmo na manutenção dos já instalados, estudos indicam que são bastante reduzidas as possibilidades de sua ocorrência. Nesse sentido, as principais causas da efetiva verificação dos referidos efeitos são atribuídas às condições de fraca visibilidade e mudanças climáticas, ainda merecendo ser considerado que o afastamento entre as torres, sua visibilidade e a velocidade de rotação das hélices garantem aos animais tempo hábil para se desviarem (FADIGAS, 2011, p. 258).

Diante disso, resta a percepção de que existe o risco de a infraestrutura necessária à geração eólica causar impactos ambientais negativos; contudo, há formas eficazes de bloqueá-los, ou ao menos minimizá-los. Nesse ponto, revela-se a importância de estudos prévios à instalação dos parques apontarem a viabilidade de sua montagem, considerando os possíveis prejuízos decorrentes de sua instalação e operação.

Tendo isso em vista, constata-se que as consequências ambientais do processo produtivo da energia são positivas, uma vez que apesar de sua potencialidade para causar prejuízos ao patrimônio natural, esses podem ser driblados, além de os benefícios dele resultantes serem significativos e merecem ser valorizados.

Partindo para a análise da potencialidade brasileira para a geração eólica - já que além de ser um dos propósitos desta sessão, dado que influencia na verificação da instrumentalidade da geração eólica para a empregabilidade verde no país, o resultado positivo da análise dos impactos ambientais decorrentes da exploração energética dos ventos a estimula - merece ser considerada sua representação gráfica, conforme demonstra a ilustração abaixo, que considera a produção a partir dos ventos captados por máquinas de rotores a 50 e 100 metros de altura: 
Gráfico 1 - Potencial eólico brasileiro
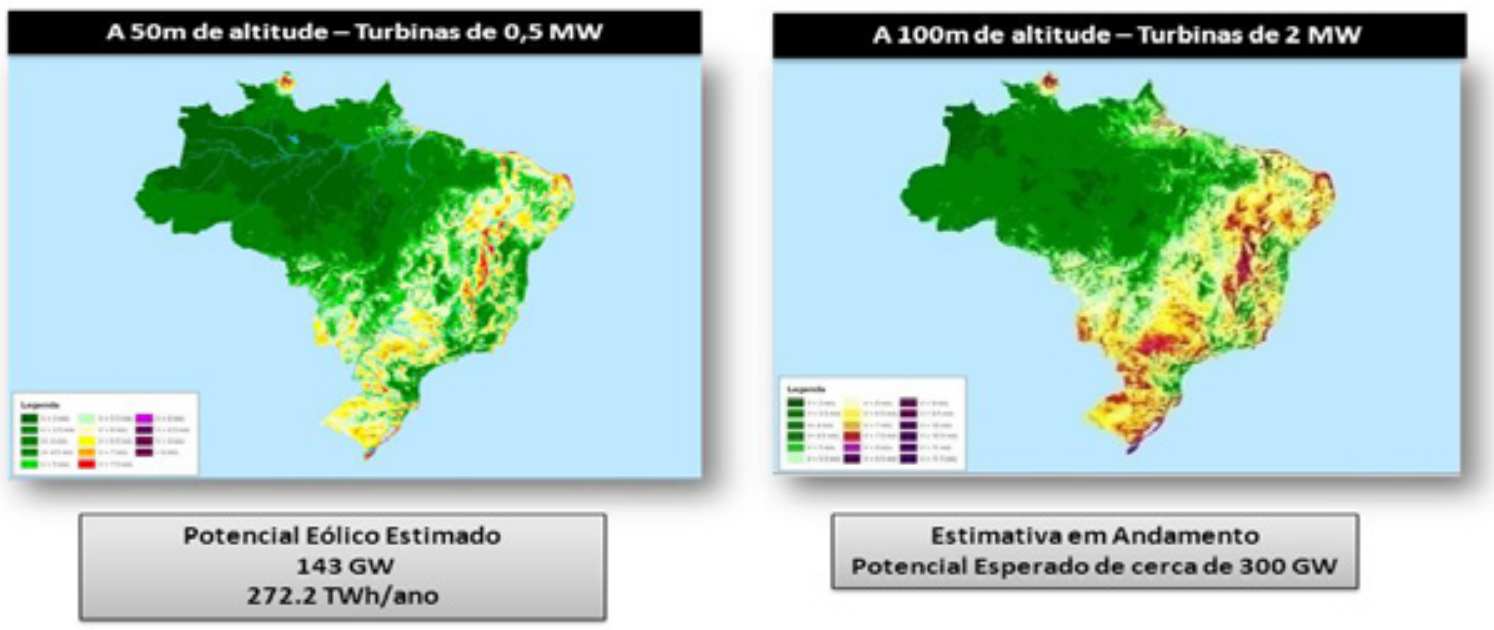

Fonte: CEPEL, 2001

Por meio da ilustração acima colacionada, verifica-se que o potencial brasileiro para a produção eólica, seja por meio de equipamentos com rotores de 50, ou mesmo de 100 metros, é notadamente elevado. Sendo detectado através das máquinas comercialmente disponíveis na época da elaboração do atlas na qual a figura está contida - cujos rotores estão a 50 metros de altura e possuem densidade média de ocupação do terreno fixada no valor conservador de $0,5 \mathrm{MW} / \mathrm{km}^{2}$-, sua medição oficial é estimada em torno de 143 GW, o que corresponde a pouco mais de 270 terawatt-hora por ano (TWh/ano).

Contudo, caso considerado o padrão atual de máquinas com rotores a 100 metros de altura, o referido potencial pátrio experimenta uma significativa ampliação, sendo estimado em mais de $300 \mathrm{GW}$, e, portanto, superando o potencial do Brasil para a produção de hidroeletricidade, conforme indica o IPCC (2011).

Tendo isso em vista, e partindo do fundamento de que tais dados constam do Atlas do Potencial Eólico Brasileiro de 2001 (primeiro atlas elaborado pela CEPEL, não tendo sido publicada uma edição mais recente do mesmo, embora a Centro se empenhe em ratificar e atualizar as informações necessárias), conclui-se que o Estado Brasileiro é notadamente rico em ventos dotados da capacidade de produzir energia. Em outras palavras, a velocidade dos ventos brasileiros na altura em que são captados demonstra que o país não somente conta com uma vasta dotação de ventos - o que é favorecido em virtude da extensão do território nacional -, mas também preenche as condições suscitadas pela indústria energética para sua utilização no processo produtivo.

Sendo assim, ratificando a ideia de que a geração eólica apresenta resultados ambientais compatíveis com a efetivação de empregos verdes e conjugando-a com o fato de o Brasil apresentar significativo potencial para explorá-la, cabe considerar sua relevância para a criação - ou mesmo para a manutenção - de empregos verdes no país.

Tendo em vista a alta nos preços da energia e produtos primários, consumidores e formuladores depolíticas estão pressionandoas empresas para queadotem práticas e métodos de produção mais limpa (fazendo referência ao Programa $\mathrm{P}+\mathrm{L}$, proposta que procura aplicar 
continuamente determinada estratégia de prevenção ambiental sobre processos, produtos e serviços com vistas ao aumento da eficiência da produção e redução dos riscos oferecidos ao homem e ao meio ambiente) (CUSTÓDIO; VALLE, 2015, p. 30). Em vista disso, argumentos voltados para o esverdeamento da economia e do mercado de trabalho estão se tornando cada vez mais poderosos, cabendo ressaltar sua relação com o clamor pela abertura de novas empresas que prezam pela preservação ambiental, desenvolvimento de novos mercados e baixos custos com energia (PNUMA, 2008).

A adequação entre o sistema produtivo da energia eólica e o $\mathrm{P}+\mathrm{L}$ evidencia a proximidade entre aquele e a enfocada empregabilidade verde. Tal constatação decorre da ideia de que o impacto ambiental provocado pela utilização da energia eólica é praticamente insignificante, notadamente ao considerar que a geração do bem invoca - como principais matérias primas - recursos que não se esgotam, bem como que não pressupõem uma depredação do ambiente natural para sua captura.

Por meio do relatório Empregos Verdes, o PNUMA (2008), ao apresentar a exploração de energias renováveis como campo fértil para empregos verdes, destacou a representatividade da energia eólica, como se vê na figura abaixo colacionada:

Figura 1: Estimativa mundial de empregos no setor de energias renováveis, países selecionados e mundo

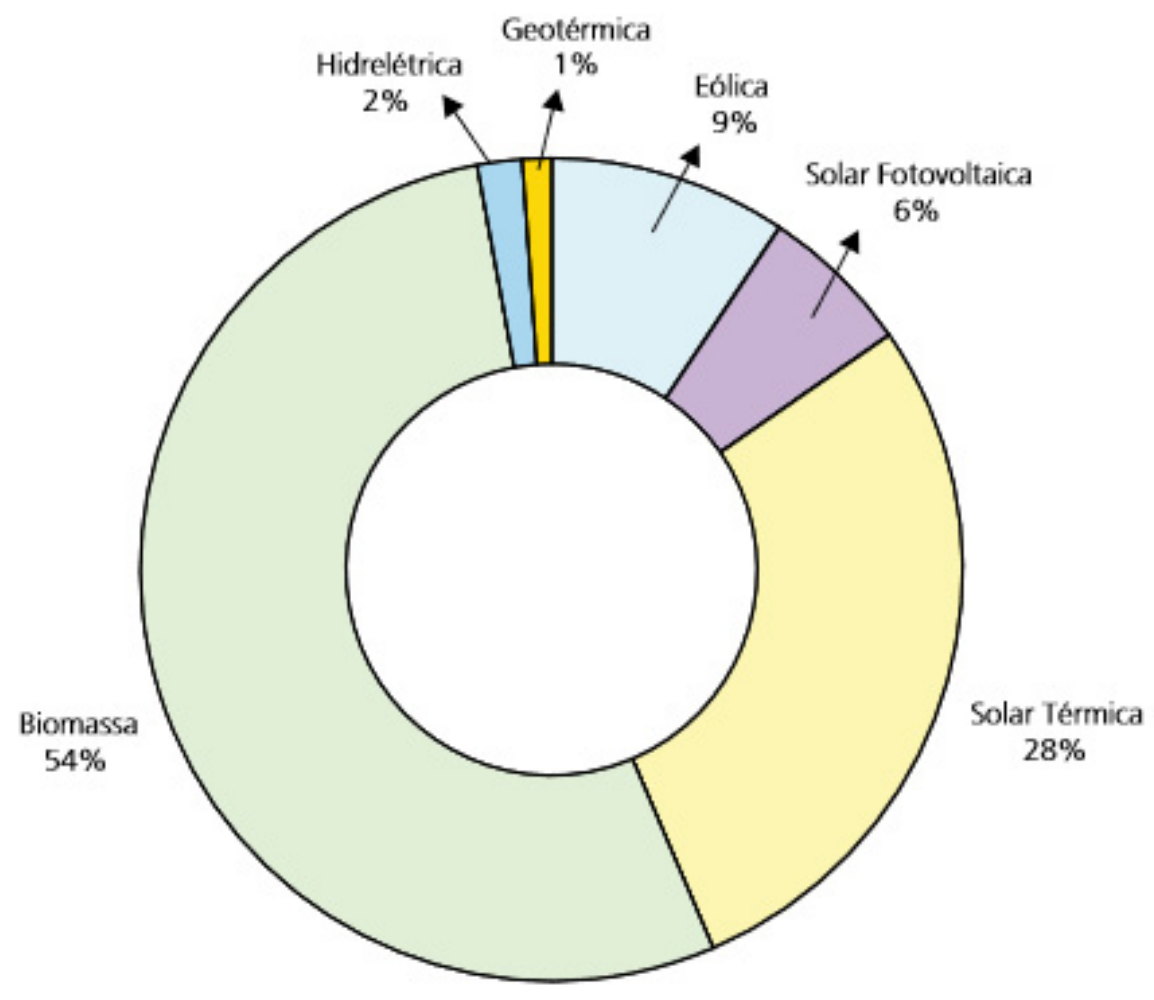

Fonte: PNUMA, 2008

Portanto, tendo em vista que a produção da energia eólica acarreta a empregabilidade emempreendimentosquedetêma capacidadedeunirocrescimentoeconômicoà preservação ambiental - alicerces da empregabilidade verde -, a exploração do potencial eólico nacional trata-se de alternativa possivelmente capaz de efetivar empregos verdes no Brasil. 
Por outro lado, considerada a equação que merece ser observada ao garantir o oferecimento de tais empregos, a qual foi objeto da segunda sessão desta pesquisa, cabe analisar se as vagas de trabalho ofertadas no setor estão de acordo com os padrões de decência laboral, motivo pelo qual o tópico seguinte é destinado a essa discussão.

\section{O LABOR NA PRODUÇÃO EÓLICA BRASILEIRA: "VERDE” APENAS SOB O VIÉS AMBIENTAL?}

Como constatado em linhas anteriores, o sistema produtivo da energia eólica apresenta potencial elevado para o oferecimento de empregos verdes, tendo em vista sua capacidade de conciliar o atendimento dos interesses econômicos que determinam a instalação e funcionamento de parques eólicos à satisfação dos anseios voltados para a preservação ou restauração do patrimônio natural. Contudo, a decência no trabalho se trata de postulado indispensável a qualquer vínculo laboral, devendo ser observado inclusive naqueles que possivelmente chamem maior atenção em virtude de seu respeito pelo meio ambiente, tais como os empregos verdes.

Especificamente quanto à relação entre empregos verdes e trabalho decente, o PNUMA (2008, p. 05), através do já referido relatório, que trata precipuamente do esverdeamento laboral, aponta que empregos verdes não constituem, necessariamente, trabalho decente. Nesse sentido, atesta que práticas inadequadas adotadas em tais formas de labor os tornam teoricamente verdes, mas desprovidos dessa característica no plano fático.

Exemplificadamente, cabe pôr em relevo oportunidades de trabalho no setor de reciclagem, onde a recuperação da matéria prima alivia a pressão sobre os recursos naturais, permitindo que sejam caracterizadas como verdes, sob a perspectiva ambiental; em contrapartida, caso tenham se valido de processos poluentes ou perigosos, podem causar danos significativos ao meio ambiente e à saúde humana - o que não ocorre raramente, tendo em vista que o labor nessa seara está marcado pela precariedade e baixa renda (PNUMA, 2008, p. 13).

Aplicando tais ideias ao propósito desta pesquisa, cabe analisar se a produção de energia por meio da exploração da força dos ventos, embora seja teoricamente capaz de oferecer empregos verdes, apenas o faz sob o ponto de vista ambiental, desprezando a garantia de condições laborais atreladas à decência necessária a qualquer trabalho.

Tendo isso em vista, passa-se a analisar possíveis intercorrências maléficas à decência laboral que sejam fruto do sistema produtivo de energia através dos ventos.

Dispensando algumas considerações acerca da remuneração percebida pelos empregados do ramo, percebe-se que, enquanto aqueles que desempenham funções de coordenação das atividades laborais, bem como de pesquisas relacionadas - sem que mantenham contato direto com a operação do sistema produtivo - percebem, em sua generalidade, salários razoáveis ou elevados (portanto, adequados ao padrão de trabalho decente), a maior parte dos empregados que lidam com o acionamento e manutenção dos equipamentos, ou mesmo com sua fabricação, não são remunerados com salários que lhes oportunizam a plena satisfação de suas necessidades básicas (PEREIRA, 
2012). Nesse diapasão, Pereira Neto (2014, p. 129) atenta para o fato de que os gastos do empreendedor eólico com o respectivo sistema produtivo e distributivo não justificam o pagamento de baixos salários aos seus operadores (o que denota o afastamento de empregos verdes, sob a perspectiva social), ainda apontando a internalização dos custos como uma saída para não provocar o desinteresse por investimentos no ramo.

Especificamente quanto à possibilidade de a geração eólica causar poluição sonora e afetar negativamente a decência do trabalho desenvolvido no setor, merece ser considerado que essa forma de poluição gera ruídos que podem causar prejuízos à saúde humana ou animal, ou seja, apresentam potencial para provocar danos. Partindo dessa ideia, o barulho decorrente da movimentação dos aerogeradores que permitem a captação dos ventos para posterior exploração do seu potencial energético pode atingir níveis superiores aos suportáveis pelo homem médio, tendo o condão de causar prejuízos à sua integridade física ou psíquica (HINRICHS; KLEINBACH, 2008).

Deve-se considerar, ainda, que a altura dos rotores, bem como a rugosidade do solo, o relevo e demais condições naturais da localidade onde está instalado o parque eólico influenciam diretamente na provocação de ruídos. Deste modo, os níveis de ruídos podem variar ao ponto de se tornarem bastante altos, ou mesmo desprezíveis. Tendo isso em vista - e considerando que o mecanismo da poluição sonora diz respeito à provocação de danos em potencial -, quando a atividade de produção eólica estiver organizada de modo que os ruídos decorrentes de sua operação ofereçam riscos de danos aos seres humanos ou animais, se torna possível considerá-la como incompatível com o oferecimento de oportunidades de trabalho decentes (SIMIONI, 2006, p. 106).

Além disso, como já foi brevemente mencionado, parques eólicos também podem provocar poluição visual (seja de maneira direta sobre a paisagem ou como decorrência das sombras produzidas pelas hélices), o que também tem o condão de repercutir negativamente sobre as condições laborais no setor, afastando a decência do trabalho no ramo. Saliente-se, contudo, que tal repercussão comumente ocorre de maneira indireta ou tangencial, estando relacionada à tentativa de minimizar ou bloquear a possibilidade de causar poluição visual.

Com efeito, o cenário natural sofre de maneira direta em virtude de abrigar a instalação de altas torres com hélices, as quais ainda podem apresentar-se de maneira colorida e com várias pás, enquanto turbinas apresentam designs chamativos e podem estar presentes em quantidade elevada (PINTO, 2013, p. 223). Oportunamente, para que seja alcançado o propósito dessa sessão, merece ser posta em foco a variedade de cores e designs impressos nos aerogeradores presentes nos parques eólicos.

Com vistas a impedir reações humanas desagradáveis à variedade de cores e designs referentes aos mencionados equipamentos, é comum a adoção de medidas, tais como: sua pintura em cores que se assemelham às da paisagem local, opção por fiação subterrânea e evitar o uso de placas de sinalização (PEREIRA NETO, 2014, p. 78). Ainda que as referidas medidas tendentes a afastar uma possível poluição visual resultante da instalação de parques eólicos sejam eficazes em seu propósito, podem causar prejuízos aos empregados do setor, denotando que o respeito do respectivo labor pelo meio 
ambiente não está acompanhado da oferta de condições decentes de trabalho.

Levando em consideração que a pintura dos equipamentos em cores semelhantes às da paisagem local, bem como a diminuta ou inexistente utilização de placas de sinalização dificultam a localização dos respectivos aerogeradores, os empregados responsáveis por seu acionamento e operação encontram maiores dificuldades para desenvolver suas atividades laborais. Considerando a altura e dureza dos instrumentos, associadas à sua baixa visibilidade, são elevados os riscos de ocorrência de acidentes de trabalho nas atividades a eles relacionadas, notadamente no período noturno ou demais momentos do dia em que a luminosidade não seja forte.

Além disso, a instalação e manutenção de fiação subterrânea importam em contato com instrumentos capazes de passar corrente elétrica. Nesse sentido, tendo em vista as consequências do contato humano com uma descarga elétrica, releva-se a periculosidade da atividade laboral considerada (PEREIRA, 2012, p. 98).

Partindo para considerar um outro aspecto da produção energética através dos ventos que detém potencialidade para afetar negativamente o resguardo de condições decentes de trabalho no ramo, dá-se momentâneo enfoque à possibilidade de interferências eletromagnéticas. Quanto a essas, vale considerar que a disposição da infraestrutura necessária à geração eólica pode dificultar a passagem de informações, notadamente ao impor obstáculos ao curso das linhas de comunicação (CUSTÓDIO; VALLE, 2015, p. 26).

Em vista disso, além de cuidadoso e minucioso, o trabalho desenvolvido no planejamento, instalação, operação ou mesmo reparo dos equipamentos que possam causar interferências eletromagnéticas é notadamente perigoso. Somando-se ao perigo natural que decorre do contato direto com tais instrumentos, a incerteza científica quanto aos danos que podem causar ao homem (como também ao meio ambiente) eleva as razões pelas quais se pode considerar o exercício das referidas atividades laborativas perigosas e, portanto, desprovidas de decência.

Ainda que a aplicação do princípio da precaução seja relevante para evitar a ocorrência de danos sérios e irreversíveis sobre os quais ainda não existe certeza científica absoluta acerca de sua efetivação, a invocação daquele não permite descaracterizar o perigo inerente às atividades laborais no sistema eólico que contatam equipamentos potencialmente causadores de interferências eletromagnéticas (CUSTÓDIO; VALLE, 2015, p. 30). Por outro lado, reitere-se a importância de aplicá-lo, uma vez que representa instrumento favorável a evitar a concretização de danos, sobretudo, ao considerar as demais possibilidades que podem fazer com que um empregado do sistema de produção eólica labore sob condições indecentes.

Saliente-se, ainda, que as mencionadas consequências indecentes do labor desenvolvido no sistema produtivo eólico merecem ser somadas à natural periculosidade do trabalho no setor, uma vez que esse está permeado por constante contato direto com eletricidade, bem como determina o acionamento e manuseio de aerogeradores bastante altos, o que importa em risco de quedas a alturas elevadas.

Embora a apresentação das mencionadas evidências relacionadas à falta de decência em atividades laborais relacionadas à geração eólica não seja taxativa, é 
suficiente para afastar a conclusão de que sua capacidade de garantir oportunidades de trabalho que não implicam em degradação ambiental está acompanhada da garantia de labor decente. Invoca-se, portanto, o reconhecimento feito pelo PNUMA (2008, p. 05) de que empregos ambientalmente sustentáveis não necessariamente constituem trabalhos decentes.

Nesse diapasão, passando a aplicar a caracterização de empregos verdes pregada pela OIT, percebe-se que vínculos laborais relativos ao sistema de produção da energia eólica não se encaixam na sua conceituação, que contempla, necessariamente, uma avaliação da sustentabilidade em suas três dimensões, a saber, a ambiental (ecológica), a econômica e a social.

Com efeito, a Organização atribui a conotação de verdes apenas aos empregos que proporcionam benefícios que ultrapassam os limites das relações de trabalho, também sendo observados nas searas previdenciária e assistencial, além de se estenderem para toda a vida do trabalhador e permitirem seu usufruto inclusive pelos seus dependentes; nesse sentido, empregos verdes passam a servistos como instrumentos que proporcionam condições para que o labor seja melhor realizado, acarretando segurança, conforto e tranquilidade ao trabalhador (OLIVEIRA; CECATO, 2016, p. 214).

Comparando tais postulados ao labor desenvolvido no processo produtivo da energia eólica, percebe-se que aqueles não estão sendo devidamente observados na efetivaçãodesse. A possibilidadedea operação da infraestrutura necessáriaàgeraçãoeólica causar poluição sonora, além dos efeitos decorrentes das tentativas de driblar a poluição visual e do contato com equipamentos que geram interferências eletromagnéticas e demais utensílios por onde passam correntes elétricas, merecem ser somados à gama de empregados do ramo que recebem baixos salários e ao risco inerente ao labor no ramo (associado à operação de instrumentos muito altos e eletrizados) para revelar que os vínculos empregatícios efetivados no setor estão permeados por condições indecentes de trabalho.

Sendo assim, considerando que a real atribuição da conotação de emprego verde a uma determinada oportunidade de trabalho vai além de analisar sua potencialidade de garantir o resguardo do patrimônio ambiental, já que também demanda a observância de circunstâncias atinente ao trabalho decente, percebe-se que o labor no sistema produtivo eólico carece de tal qualificação. Por outro lado, cabe considerar que estudos e pesquisas atinentes à infraestrutura de parques eólicos e sua operação têm o condão de elaborar projetos relativos ao respectivo sistema produtivo adequados à decência laboral, aprimorando as condições de trabalho no ramo e garantindo que ofereça empregos verdes, tais como esses merecem ser considerados.

\section{CONCLUSÃO}

O reconhecimento de que a própria sobrevivência e bem estar do homem demandam o contínuo usufruto dos recursos naturais tem se associado à necessidade de garantir decência às diversas oportunidades de trabalho para relevar a importância de concretizar e manter atividades laborais que além de não resultarem em prejuízos à 
integridade ambiental, tornam possível a efetivação do direito fundamental ao trabalho decente. Em vista disso, tem se difundido a relevância dos empregos verdes, os quais aproximam ecologia e economia.

Por outro lado, considerando que sua observância demanda a existência de condições naturais favoráveis - associadas ao desenvolvimento de pesquisas e políticas ativas -, sua implementação está relacionada ao potencial individual de cada atividade, ainda considerando a localidade onde será desenvolvida. Especificamente no que tange às atividades relacionadas ao sistema produtivo de energia, esta pesquisa permitiu a constatação de que seu desenvolvimento sob uma ótica sustentável - notadamente ao prezar pela utilização de fontes renováveis - torna o setor energético ramo marcadamente favorável à empregabilidade verde.

Tendo em vista que o Brasil apresenta número considerável de pessoas que permanecem à margem do mercado de trabalho decente, além de dotação significativa de recursos energéticos que poderiam ser utilizados para a produção de energia renovável, o interesse acerca do fomento de empregos verdes no país motivou a investigação sobre a maior exploração da energia eólica brasileira. Nesse diapasão, ainda que sua efetivação possa resultar em poluição sonora e visual, além de provocar interferências eletromagnéticas, as vantagensadvindas da renovabilidade da produçãoe mínimos impactosambientais negativos decorrentes da utilização das respectivas matérias primas têm o condão de demonstrar o potencial do ramo para a empregabilidade verde, mormente ao considerar as técnicas que bloqueiam as possíveis decorrências negativas referidas.

Por outro lado, a ausência de considerações laborais decentes impede o reconhecimento do sistema produtivo eólico nacional como adequado ao oferecimento de empregos verdes. A baixa remuneração de significativa parcela dos empregados do ramo, somada aos perigos que correm em virtude no manuseio e operação de equipamentos muito altos ou que transmitem corrente elétrica, além de sofrimento com os efeitos da poluição causada, impedem considerar a geração eólica brasileira favorável à empregabilidade verde.

Contudo, levando em consideração os benefícios que a aproximação entre a ecologia e a economia, através do esverdeamento laboral, pode acarretar, importante se revela o redirecionamento da produção de energia por meio dos ventos nacionais valendo-se de estudos e políticas direcionados -, de modo a garantir que a exploração do significativo potencial eólico pátrio dê sua parcela de contribuição à difusão de empregos verdes no Brasil, assim como já é possível perceber em Estados europeus e norte-americanos.

\section{REFERÊNCIAS}

BETINI, Roberto Cesar; CASTAGNA, Annemarlen Gehrke; TIEPOLO, Gerson M. O Emprego Verde e o Desenvolvimento Sustentável. In: VIII Congresso Brasileiro de Planejamento Energético. Curitiba, 2012. Disponível em: $<$ https://www.researchgate. net/publication/275951532_O_Emprego_Verde_e_o_Desenvolvimento_Sustentavel >. Acesso em: 05 set. 2017. 
CEPEL. Atlas do Potencial Eólico Brasileiro. 2001. Disponível em: < http://www. cresesb.cepel.br/publicacoes/download/atlas_eolico/Atlas\%2odo\%2oPotencial\%20 Eolico\%2oBrasileiro.pdf >. Acesso em: 20 ago. 2017.

CUSTÓDIO, Maraluce Maria; VALLE, Cíntia Nogueira de Lima. Energia renovável, energia alternativa e energia limpa: breve estudo sobre a diferenciação dos conceitos. In: CUSTÓDIO, Maraluce Maria (Org.) Energia e Direito: perspectivas para um diálogo de sustentabilidade. Rio de Janeiro: Lumen Juris, p. 05-39, 2015.

CRUZ, Paulo Márcio; BODNAR, Zenildo (Org.). Globalização, transnacionalidade e sustentabilidade. Itajaí: UNIVALI, 2012. Disponível em: < http://www.univali.br/ppcj/ ebook >. Acesso em: o5 mai. 2013.

FADIGAS, Eliane Aparecida Faria Amaral. Energia eólica. São Paulo: Manole, 2011.

GIDDENS, Anthony. A Política da Mudança Climática. Tradução de Vera Ribeiro. Rio de Janeiro: Zahar, 2010.

HINRICHS, Roger A.; KLEINBACH, Merlin. Energia e Meio Ambiente. Tradução da $3^{\text {a }}$ ed. norte americana. São Paulo: Cengage Learning, 2008.

INTERGOVERNMENTAL PANEL ON CLIMATE CHANGE - IPCC. Special report on renewable energy sources and climate change mitigation, 2011. Disponível em: < http://srren.ipcc-wg3.de/report/IPCC_SRREN_Full_Report.pdf >. Acesso em: 03 set. 2017.

KRAMER, Andrea S.; FUSARO, Peter C. Energy and Environmental Projec Finance Law and Taxation: New Investement Techniques. New York: Oxford University Press, 2010 .

LOPEZ, Ricardo Aldabó. Energia eólica. 2. ed. São Paulo: Artliber, 2012.

OIT. Promover la seguridad y la salud en una economía verde. Ginebra: Oficina Internacional del Trabajo, 2012. Disponível em: < http://www.ilo.org/wcmsp5/groups/ public/@ed_protect/@protrav/@safework/documents/presentation/wcms_17818o.pdf >. Acesso em: 17 jul. 2016.

Trabajo decente y la agenda 2030 de desarrollo sostenible. Ginebra: Departamento de Comunicación e Información Pública, 2017. Disponível em: < http:// www.ilo.org/wcmsp5/groups/public/---dgreports/---dcomm/documents/publication/ wcms_470340.pdf > . Acesso em: 17 ago. 2017.

OLIVEIRA, Flavia de Paiva Medeiros de; CECATO, Maria Aurea Baroni. Trabalho decente e emprego verde: uma análise à luz do caráter pluridimensional da sustentabilidade. 
In: Revista de Direito e Sustentabilidade [online]. Curitiba, vol. 02, no 02, p. 207225, 2016. Disponível em: < http://www.indexlaw.org/index.php/revistards/article/ view/1308/1735 >. Acesso em: o5 set. 2017.

PEREIRA, Osvaldo Soliano. Energia eólica: segunda fonte de energia elétrica do Brasil. In: VEIGA, José Eli da (Org.) Energia eólica. São Paulo: Senac, 2012. p. 87-207.

PEREIRA NETO, Aloísio. A energia eólica no direito ambiental brasileiro. Rio de Janeiro: Synergia Editora, 2014.

PINTO, Milton de Oliveira. Fundamentos de energia eólica. Rio de Janeiro: LTC, 2013.

PROGRAMA DAS NAÇÕES UNIDAS PARA O MEIO AMBIENTE - PNUMA. Empregos verdes: Trabalho decente em um mundo sustentável e com baixas emissões de carbono. 2008. Disponível em: < http://www.oitbrasil.org.br/sites/default/files/topic/green_job/ pub/empregos_verdes_rumos_257.pdf >. Acesso em: o1 set. 2017.

SEN, Amartya K. Desenvolvimento como liberdade. São Paulo: Companhia de Bolso, 2010.

SIMAS, Moana; PACCA, Sérgio. Energia Eólica, geração de empregos e Desenvolvimento Sustentável. In: Estudos avançados [online]. São Paulo, vol. 27, n 77, p. 99-115, 2013. Disponível em: < http://dx.doi.org/10.159o/So103-40142013000100oo8 >. Acesso em: 04 set. 2017.

SIMIONI, Carlos Alberto. O uso de energia renovável sustentável na matriz energética brasileira: obstáculos para o planejamento e ampliação de políticas sustentáveis. $314 \mathrm{f}$. Tese (Doutorado) - Universidade Federal do Paraná. Curitiba, 2006. Disponível em: < http://acervodigital.ufpr.br/bitstream/handle/1884/508o/Carlos\%2oAberto\%2oSimioni. pdf?sequence=1\%25E2\%2589\%25A5 > Acesso em: 02 set. 2017.

SOUZA, Lívia Maria Cruz Gonçalves de; TEIXEIRA, Karen Myrna Castro Mendes. Utilização da energia geotérmica como instrumento de alcance para a sustentabilidade na perspectiva intergeracional. In: CUSTÓDIO, Maraluce Maria (Org.) Energia e Direito: perspectivas para um diálogo de sustentabilidade. Rio de Janeiro: Lumen Juris, p. 77-98, 2015. 